\title{
O sujeito afetivo e os ambientes virtuais de aprendizagem*
}

\author{
Magalí Teresinha Longhi \\ Patricia Alejandra Behar \\ Magda Bercht \\ Programa de Pós-Graduação em Informática na Educação \\ Universidade Federal do Rio Grande do Sul (UFRGS) \\ Caixa Postal 5071 - 90.041-970 - Porto Alegre - RS - Brasil \\ mlonghi@cesup.ufrgs.br, berchteinf.ufrgs.br, pbehareterra.com.br
}

Resumo: Este artigo apresenta correspondências entre as teorias de Piaget e de Scherer no que diz respeito à definição do sujeito afetivo e aos aspectos emocionais envolvidos em um ambiente virtual de aprendizagem (AVA). O reconhecimento da dimensão afetiva do aluno nesses ambientes é recurso importante para a prática de um professor em Educação a Distância. Neste trabalho, a dimensão afetiva é caracterizada pelos estados de ânimo manifestados durante as interações no espaço virtual.

Palavras-chave: sujeito afetivo, sujeito psicológico, fenômenos afetivos, estados de ânimo, ambiente virtual de aprendizagem

\section{Affective Subject and the Virtual Learning Environments}

Abstract: This paper presents correlations between the theories of Piaget and Scherer as regards the definition of the subject's affective and emotional aspects involved in a virtual learning environment (AVA). The recognition of the affective dimension of students in these environments is important resource for the practice of a teacher in distance education. In this work, the affective dimension is characterized by moods expressed during interactions in virtual space.

Key-words: Affective subject, psychological subject, affective phenomena, mood, virtual learning environments

\section{Introdução}

Este trabalho examina elementos das teorias de Piaget (2005) e Scherer (2005) capazes de fornecer subsídios para a especificação dos aspectos afetivos envolvidos em Ambiente Virtuais de Aprendizagem (AVA).

Entende-se por AVA um "espaço na internet, formado pelos sujeitos e suas interações e formas de comunicação que se estabelecem por meio de uma plataforma [...]" (Behar, 2009; p. 29). Essa plataforma é constituída por uma infra-estrutura tecnológica (interface gráfica, ferramentas de comunicação síncrona/assíncrona e outras funcionalidades) e por todas as relações estabelecidas pelos sujeitos (Behar et al., 2005) nesse ambiente. Tais relações (cognitivas, afetivas e simbólicas) se estabelecem a partir da estratégia aplicada pelo professor, de acordo com um determinado modelo pedagógico ${ }^{1}$. Elas se sustentam (ou não) conforme os elementos motivadores suscitados pelos atores do processo educacional.

$\mathrm{Na}$ teoria piagetana, o desenvolvimento cognitivo ocorre em função de três fatores inter-relacionados, que definem o sujeito psicológico: orgânicos, mentais e sociais. As interações são entendidas com base nos pressupostos de Piaget (1973), em que o conhecimento é construído a partir da interação do sujeito psicológico e o meio. Para o autor, os fatores mentais desdobram-se em aspectos cognitivos, afetivos e simbólicos (linguagem), os quais, embora distintos, são totalmente indissociáveis.

V. $7 \mathrm{~N}^{\circ} 3$, dezembro, 2009 


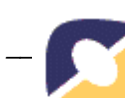

O sujeito psicológico, segundo Dolle $(1979,1993)$, inspirado por Piaget, é formado pelos sujeitos: social, afetivo, cognitivo e biofisiológico. Para explicar o sujeito psicológico no espaço virtual, Behar (1999) apresenta um modelo de interação entre o sujeito e o ambiente computacional. Sugere uma resignificação da dimensão biofisiológica e propõe o sujeito-AVA. No ambiente virtual, o sujeito age por meio do hardware e software e, portanto, deve conhecer as tecnologias pertinentes à interação. Assim, a partir da avaliação sujeitoAVA, o sujeito tecnológico passa a ser a quarta dimensão do sujeito psicológico, conforme indicado por Bassani (2006), por sua vez baseado em Behar (1999).

O sujeito afetivo é representado não só pela relação com os outros sujeitos formadores do sujeito-AVA, mas por todos os componentes orgânicos que participam na avaliação e ativação de um fenômeno afetivo. A teoria de Scherer (2001) pressupõe que o sujeito afetivo é formado por componentes orgânicos, em que o entendimento dos processos envolvidos pode explicar os diversos fenômenos afetivos experimentados pelo sujeito psicológico. É na teoria de Scherer que se buscam subsídios para identificar os estados de ânimo, fatores estes associados à forma de processamento cognitivo e à reoganização da informação na memória.

Nesta perspectiva, tem-se como fundamentação teórica os estudos empreendidos por Dolle $(1993 ; 1979)$ e Behar (1999) no que se refere à dimensão afetiva e tecnológica do sujeito psicológico; e por Scherer $(2001 ; 2005)$ no que tange à definição dos componentes que participam do sujeito afetivo. Assim, propõe-se, através desta investigação, apresentar as conexões entre a abordagem teórica e os dados coletados em um AVA, no caso o ROODA ${ }^{2}$, com o propósito de avaliar a possibilidade de reconhecer a dimensão afetiva em tal ambiente. Neste trabalho, a dimensão afetiva é caracterizada a partir dos estados de ânimo do aluno evidenciados durante as interações no espaço virtual.

Na próxima seção, são mapeadas as interações entre os sujeitos psicológicos em um ambiente virtual. Na Seção 3, é abordada a epistemologia da afetividade. Na Seção 4, é feito um breve relato do modelo CPM, que explica como um fenômeno afetivo é processado. Na Seção 5, a influência dos estados de ânimo na aprendizagem é tratada; enquanto que, na Seção 6, apresenta-se o mapeamento do sujeito afetivo no ambiente virtual ROODA. Por último, na Seção 7, são feitas as considerações finais.

\section{Mapeamento das interações em um Ambiente Virtual de Aprendizagem}

O ambiente virtual de aprendizagem constitui um novo meio de interação entre os sujeitos psicológicos. Dolle (1993) define meio como um sistema formado por sujeitos, objetos e regras (Figura 1). Os sujeitos ou pessoas são os usuários do ambiente (aluno, professor, tutor). Os objetos artificiais $^{3}$ referem-se aos recursos disponibilizados nos ambientes, tais como, os conteúdos, os fóruns, os batepapos, etc. As regras institucionais regem as relações interindividuais no ambiente, como também a forma de utilização das ferramentas disponibilizadas.

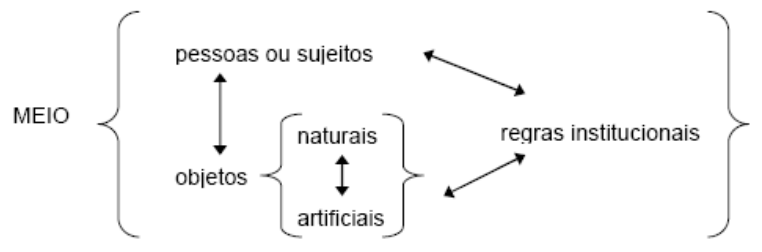

Figura 1. Esquema de representação do meio** (Dolle, 1993; p. 37)

O sujeito psicológico de Dolle (Figura 2) é constituído pelo sujeito biofisiológico, ou tudo o que diz respeito ao corpo, isto é, todas as funções biológicas e fisiológicas (genética, neurologia, neurobiologia, bioquímica, etc.); pelo sujeito cognitivo, que, enquanto age, 


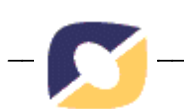

adquire conhecimentos sobre si e sobre o meio; pelo sujeito afetivo, de onde repercute a atividade sob a forma de emoções, sentimentos ou efeitos das relações estabelecidas; e, pelo sujeito social, que é a interiorização dos hábitos, das regras e dos interditos sociais de qualquer tipo.

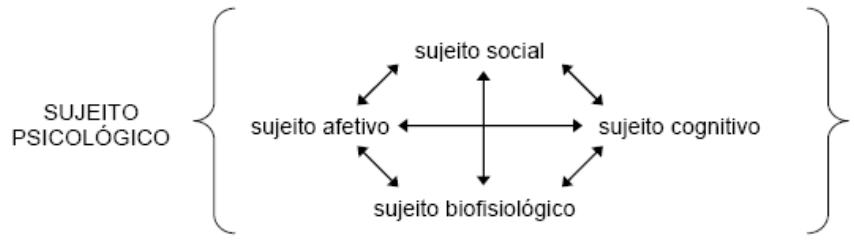

Figura 2. Esquema de representação do sujeito psicológico** (Dolle, 1993; p. 39);

A partir dos elementos constituintes do meio e do sujeito psicológico, parte-se para o esquema interacionista sujeito $\Leftrightarrow$ meio, em que é possível definir-se um modelo de mapeamento das interações apresentado na Figura 3.

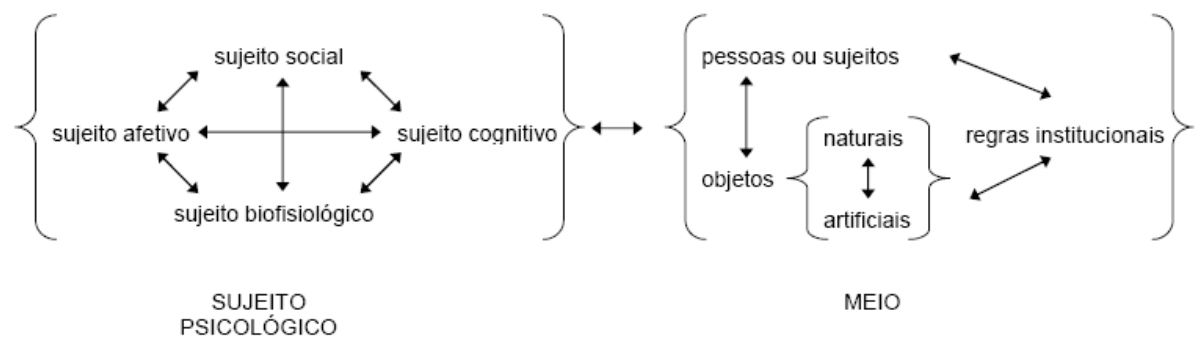

Figura 3. Gráfico da relação sujeito psicológico e meio (Bassani, 2006; p. 46)

Sendo assim, o sujeito psicológico usuário relaciona-se com o meio ambiente virtual de aprendizagem (AVA) considerando a presença de outros sujeitos psicológicos, como também os recursos disponibilizados no meio e as regras, explícitas ou não, que conduzem ou orientam as relações nesse ambiente. A partir dessas considerações e do referencial proposto por Dolle (1993, 1979), Bassani (2006) representa a interação sujeito-usuário $\Leftrightarrow$ ambiente, conforme ilustrado na Figura 4.

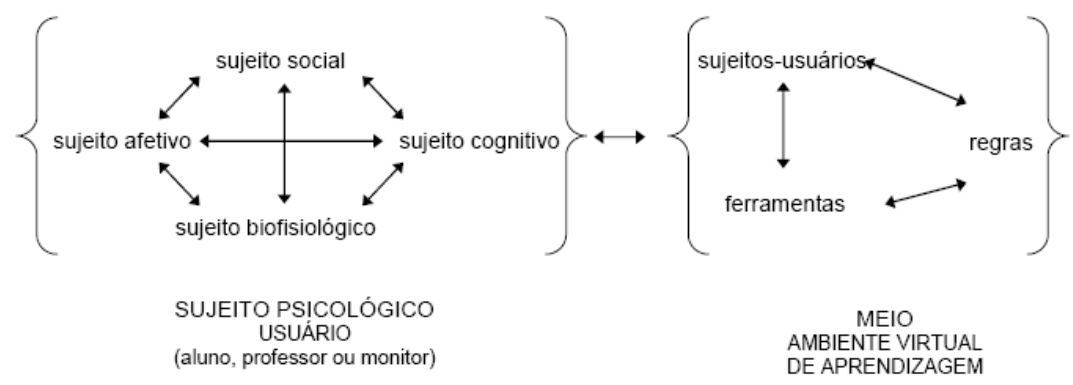

Figura 4. Representação da interação sujeito $\Leftrightarrow$ meio (Bassani, 2006; p. 120)

Behar (1999), com base nos fatores mentais (cognitivo, afetivo e simbólico) propostos por Piaget (1973), apresenta um modelo para retratar o processo de interação de um sujeito psicológico com uma ferramenta computacional. Desse modo, Behar (1999) define o sujeito tecnológico. Tal conceito é utilizado por Bassani (2006) para ressignificar o sujeito biofisiológico, "uma vez que o sujeito-usuário de um AVA relaciona-se com o meio fazendo uso do hardware e software específico" (Bassani, 2006; p. 123). Conforme ilustrado na Figura 5, o sujeito psicológico é redefinido como um sujeito-AVA. 


\section{Epistemologia da afetividade}

Piaget (1978) dedicou-se a investigar o processo de aquisição do conhecimento, e de como o mesmo se desenvolve. Desse modo, destacou, na atividade do sujeito (S), tanto o que dele se origina quanto o que provém do objeto $(\mathrm{O})$. Isto é, a relação $\mathrm{S} \Leftrightarrow \mathrm{O}$.

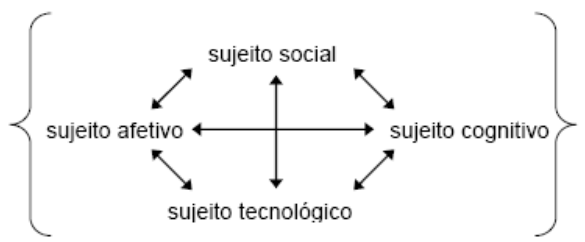

Figura 5. Representação do sujeito-AVA (Bassani, 2006)

A partir disso, o autor distingue a abstração empírica da reflexionante. A primeira, "se apoia sobre os objetos físicos ou sobre os aspectos materiais da própria ação, tais como movimentos, empurrões, etc." (Piaget, 1995; p. 5). Já a segunda, ao contrário, "apoia-se sobre tais formas e sobre todas as atividades cognitivas do sujeito (esquemas ou coordenações de ações, operações, estruturas, etc.), para delas retirar certos caracteres e utilizá-los para outras finalidades (novas adaptações, novos problemas, etc.) (Piaget, 1995, p. 6).

A abstração reflexionante, analisada a partir dos graus de reflexionamentos, comporta dois aspectos: o reflexionamento propriamente dito, em que o sujeito, nos vários estádios ${ }^{4}$, elabora uma projeção ao patamar superior daquilo que foi retirado do patamar inferior; e a reflexão, ou o ato mental de reconstrução e reorganização sobre o patamar superior daquilo que foi transferido do inferior (Piaget, 1995). A formação de cada patamar pode ser representada por um processo em espiral, conforme demonstrado na figura 6(a).

Portanto, o reflexionamento está relacionado ao processo de assimilação, ao passo que a reflexão, vincula-se ao da acomodação. O sujeito age sobre o objeto, assimilando-o. O objeto assimilado é transformado e transforma o sujeito, ao modificar suas estruturas mentais antigas para acomodar o novo conhecimento. O aspecto afetivo está no interesse em apreender o objeto ao self (o aspecto cognitivo é a compreensão); já na acomodação, a afetividade está ligada ao interesse pelo objeto novo (o aspecto cognitivo está no ajuste dos esquemas de pensamento ao fenômeno) (Arantes, 2003).

Piaget (2005) advertiu que não há um estado puramente cognitivo, tampouco um puramente afetivo. Reconheceu que a afetividade é o agente motivador da atividade cognitiva e estabeleceu duas interpretações para as relações entre afetividade e cognição: na primeira, a afetividade "explica a aceleração ou retardamento [...]; aceleração no caso de interesse $e$ necessidade, retardamento quando a situação afetiva é obstáculo para o desenvolvimento intelectual" e, na segunda, a afetividade "produz ou pode causar a formação de estruturas cognitivas" (p. 17).

A hipótese de Dolle (1979) é que a afetividade é conduzida sob uma lógica parecida com a dos processos cognitivos, comportando estruturas, estruturações e um desenvolvimento semelhante a dos estádios cognitivos. Durante o processo de desenvolvimento individual, as duas lógicas acontecem de forma sincrônica, prevalecendo ora a atualização da afetividade (potencializando a cognição), ora a atualização da cognição (potencializando a afetividade). Dessa forma, o sujeito reestrutura os fundamentos da sua relação com o mundo (Dolle, 1979; p.50), em que a inteligência reconstitui-se depois que a afetividade estar ela própria constituída (afetividade $\Leftrightarrow$ inteligência $\Leftrightarrow$ afetividade $\Leftrightarrow$ inteligência). Assim, o sujeito biofisiológico conduz ao sujeito afetivo, e este ao cognitivo por integrações e superações, seguindo uma hierarquia em espiral (Dolle, 1993), conforme apresentado na Figura 6(b). 
Neste trabalho, entende-se o termo cognição não só pelo viés do processamento de informações ou do funcionamento mental, mas também pela capacidade de reagir ao que se percebe no mundo interno e externo. Isto inclui, além do sujeito cognitivo, o afetivo, o social e o biofisiológico. Em termos epistemológicos do conhecimento, não se pode discutir acerca de reflexionamentos e reflexões sem tratar de socializações e adaptações afetivas. A Figura 7 ilustra o entrelaçamento do sujeito cognitivo com o afetivo.

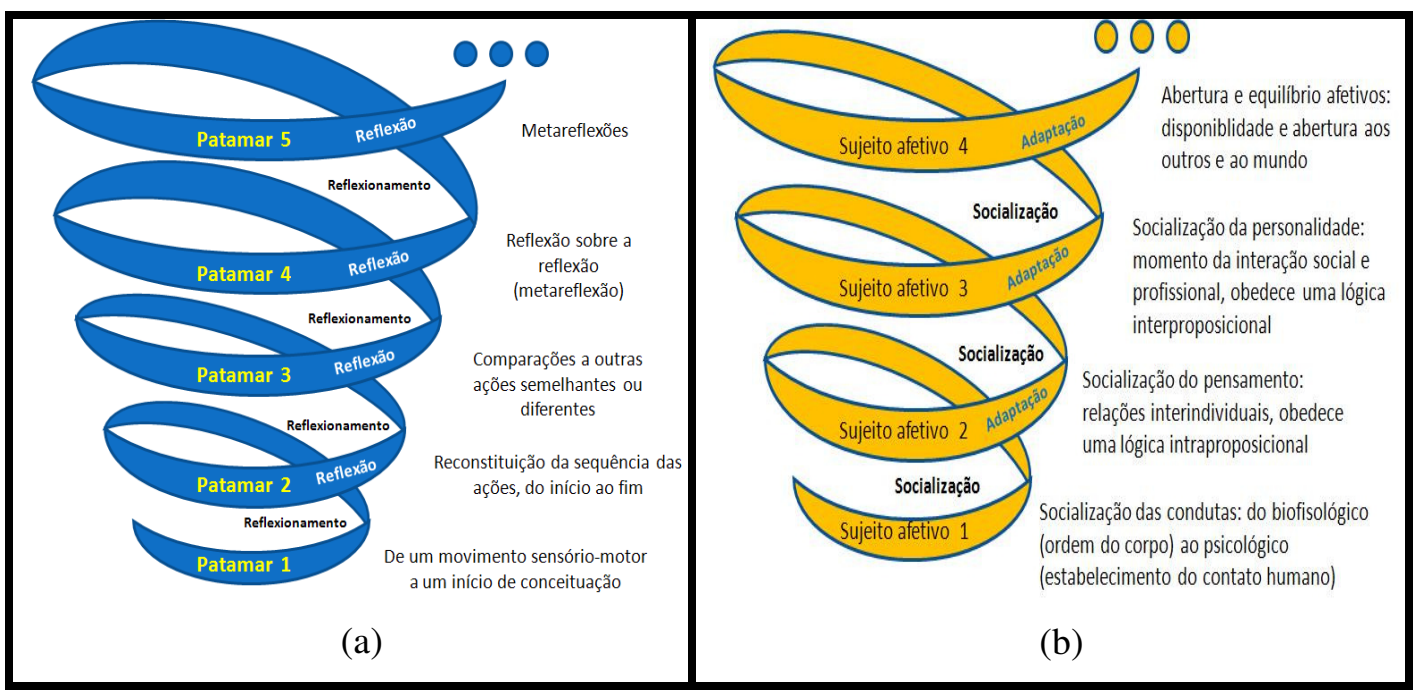

Figura 6. Representação (a) dos graus de reflexionamentos e (b) dos estádios do sujeito afetivo***

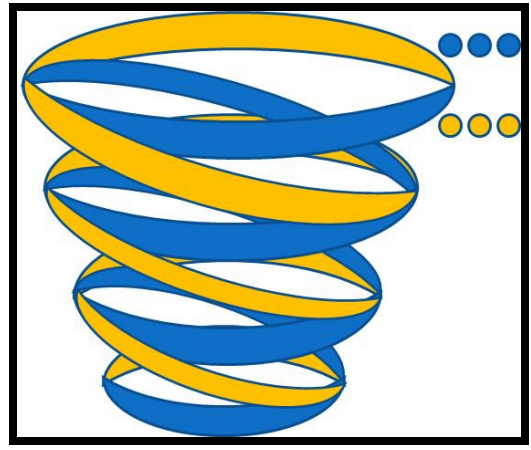

Figura 7. Entrelaçamento entre os sujeitos cognitivo e afetivo***

Por outro lado, busca-se apoio na teoria de Scherer (2001) para diferenciar e entender como os fenômenos afetivos são processados nos subsistemas orgânicos. Desse modo, pretende-se determinar os estados de ânimo e identificar quais deles estão mais relacionados à aprendizagem.

\section{A teoria de Scherer sobre a afetividade}

$\mathrm{O}$ termo afetividade, de um modo geral, refere-se à habilidade para experimentar sentimentos positivos ou negativos, e a eles reagir. É empregado no sentido da identificação dos fenômenos psíquicos e físicos, que incluem "o domínio das emoções propriamente ditas, dos sentimentos das emoções, das experiências sensíveis e, principalmente da capacidade em se poder entrar em contato com sensações" (Bercht, 2001 p.59). Os termos, tais como emoção, estados de humor ou de ânimo, motivação, sentimento, paixão, amor, personalidade, temperamento e outros tantos dizem respeito à afetividade.

Scherer (2005) concebe os termos relacionados à afetividade como fenômenos afetivos. Um fenômeno pode ser um estado (disposição do indivíduo em um dado momento) V. $7 \mathrm{~N}^{\circ}$ 3, dezembro, 2009 
ou um processo (sequência de estados ou sucessão de mudanças que podem transformar a disposição do indivíduo). Já o termo emoção, em seu caráter popular, refere-se ao conjunto dos fenômenos afetivos.

Para definir e diferenciar os fenômenos afetivos, Scherer (2005) estabeleceu critérios para classificá-los em: 1) preferências (simpatia, antipatia), 2) atitudes (ódio, estima, desejo), 3) estados de ânimo (animado, contente, satisfeito, disposto, desanimado, abatido, insatisfeito, sofrido, indiferente, desatento, esperançoso), 4) disposições afetivas ou traços de personalidade (nervoso, ansioso, irritadiço, despreocupado, negligente, taciturno, melancólico, hostil, belicoso, rabugento, ranzinza, invejoso, ciumento, curioso, flexível, ativo, inseguro, depressivo, desconfiado), 5) posturas interpessoais ou estilos afetivos (educado, reservado, frio, caloroso, incentivador, desdenhoso, organizado, sociável, cortês), 6) emoções utilitárias (raiva, medo, alegria, tristeza, aversão, vergonha, culpa) e 7) emoções estéticas (admiração, êxtase, fascinação, harmonia, discórdia, solenidade, surpresa, persuasão).

Leventhal e Scherer (1987) propuseram uma estrutura multicamada para explicar o processamento emocional. O nível sensório-motor inclui um conjunto de programas inatos e sistemas de ativação cerebral estimulados automaticamente, sem esforço volitivo, mediante mudanças internas e externas do sujeito. O nível esquemático é automático, e integra os processos avaliados no nível anterior (sensório-motor) com imagens armazenadas de situações emocionais já ocorridas (memória da experiência emocional). O nível conceitual ativa a memória para comparar dois ou mais episódios emocionais. Esses três níveis correspondem aos estádios do desenvolvimento cognitivo postulados por Piaget.

Em cada um dos níveis, o processamento envolve uma avaliação de forma seqüencial em etapas: (1) a relevância do evento; (2) a valência hedonista ou a implicação do evento no bem-estar e alcance imediato dos objetivos; (3) o potencial de coping ou a capacidade de superação (ou enfrentamento) que o sujeito é capaz de produzir; e (4) o significado do evento, a partir das regras sociais e valores do sujeito. Esta avaliação é conhecida por processo de appraisal ${ }^{5}$.

Segundo o modelo de Scherer (2001), também conhecido como Component Process Model (CPM), os fenômenos afetivos são explicados a partir da avaliação de um evento condutor de um episódio emocional (Figura 8). O sujeito psicológico constantemente faz uma varredura no ambiente externo e interno para detectar, avaliar e reavaliar mudanças (processo de appraisal). Em cada etapa do processo de appraisal (Relevância, Valência hedonista, Coping e Significação) são projetadas informações aos outros componentes orgânicos (Suporte, Executivo, Comunicação e Monitor), para serem ou não processadas.

Ao perceber um evento, o sujeito psicológico necessita de uma atenção mínima, reorganizada conforme a relevância do evento, sendo esta o primeiro filtro seletivo do processo de appraisal. Então, se o evento for importante para os objetivos do sujeito psicológico, tal informação é repassada para os outros componentes, que podem ou não desencadear o tipo de reação fisiológica, a ação a ser executada, a forma de expressão e indicação de sentimento subjetivo. E assim, sucessivamente, para cada etapa do processo de appraisal. $\mathrm{O}$ modelo de appraisal CPM propõe que mudanças dos eventos internos e externos mantêm uma recursividade, até que o subsistema monitor sinalize a conclusão ou ajuste do sentimento resultante para o episódio emocional avaliado (Sander et al., 2005). 


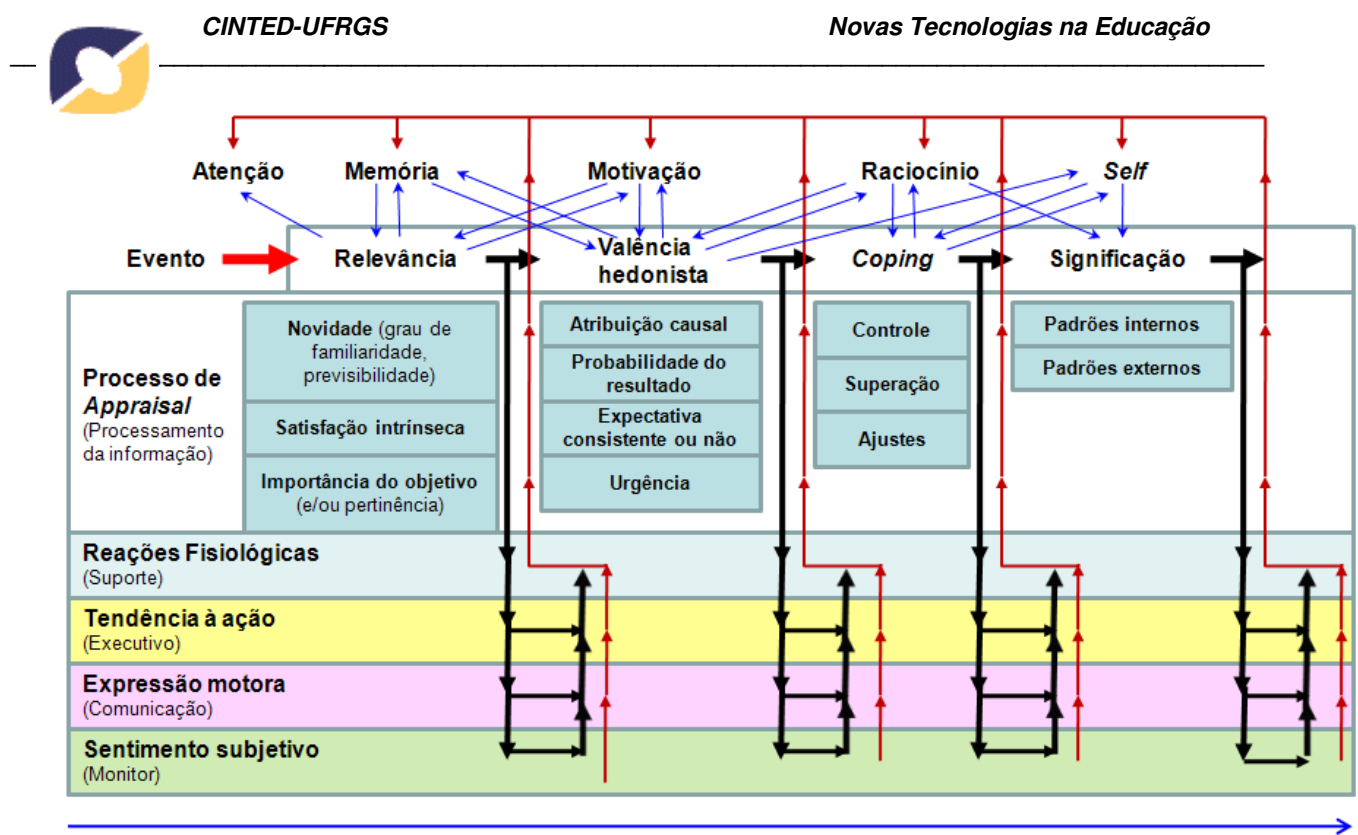

Figura 8. O modelo CPM ou modelo de Scherer (Sander et al., 2005)

\section{Os estados de ânimo na aprendizagem}

O modelo de Scherer é apropriado para definir e explicar vários fenômenos afetivos. Dentre eles, os estados de ânimo, que podem impulsionar, inibir ou dificultar o aprendizado. Podem ser pensados como um sumário de respostas afetivas (Mayer \& Hanson, 1995), os quais incluem os diversos componentes de avaliação (cognitiva, fisiológica, expressividade, motivacional e subjetiva) que o sujeito realiza.

$\mathrm{Na}$ perspectiva de como os estados de ânimo influenciam a memória e a aprendizagem, Bower (1981) formulou uma importante teoria - a Teoria de Rede de Bower. $\mathrm{O}$ autor partiu da hipótese de que um evento seria representado na memória em um cluster $^{6}$ de proposições. Estas proposições seriam registradas na memória quando do estabelecimento de associações entre o episódio afetivo vivenciado e os conceitos cognitivos que participaram do evento, sugerindo que haveria uma congruência do estado de ânimo. Para Bower, a correspondência entre o valor afetivo de uma informação e o estado de ânimo do sujeito durante sua exposição concorre para a sua apreensão ou não na memória. Tal hipótese conta com grande sustentação experimental (ver os trabalhos em Mayer \& Hanson (1995) e Pergher et alli (2005)).

A partir dos conceitos piagetianos sobre assimilação e acomodação e da teoria de Dolle sobre a afetividade (baseada em Piaget), pode-se relacionar os estados de ânimo ao desempenho cognitivo. Os estados de ânimo positivos apoiam os processos de assimilação, gerando novas crenças ou reelaborando as existentes. No processo de acomodação, eles modificam mais rapidamente os esquemas mentais já existentes. Por outro lado, os negativos, podem dificultar a incorporação de novos dados nos esquemas operatórios ou de ação ou, por outro lado, encorajar o aluno a atualizar suas crenças em face ao novo conhecimento. Já quando relacionados à ativação do processo de acomodação, podem dificultar os mecanismos de adaptação que estruturam e impulsionam o desenvolvimento cognitivo.

\section{Mapeamento do sujeito afetivo em um ambiente virtual de aprendizagem}

Nas seções anteriores, a fundamentação teórica apresentada reúne subsídios para a análise das interações no AVA ROODA, visando mapear a dimensão afetiva a partir dos sujeitos cognitivo e tecnológico. Parte-se das teorias piagetiana principalmente a referenciada por Dolle e a de Scherer para buscar evidências do sujeito afetivo no sujeito-AVA construído por Behar (1999) e Bassani (2006). Embora no sujeito-AVA a dimensão biofisiológica de Dolle tenha sofrido uma ressignificação (sujeito tecnológico), neste trabalho ela volta a ser 
aplicada, pois se verifica a importância dos componentes orgânicos na construção do sujeito afetivo, conforme apresentado na teoria de Scherer. Assim, sugere-se que o sujeito-AVA tenha a representação ilustrada na Figura 9.

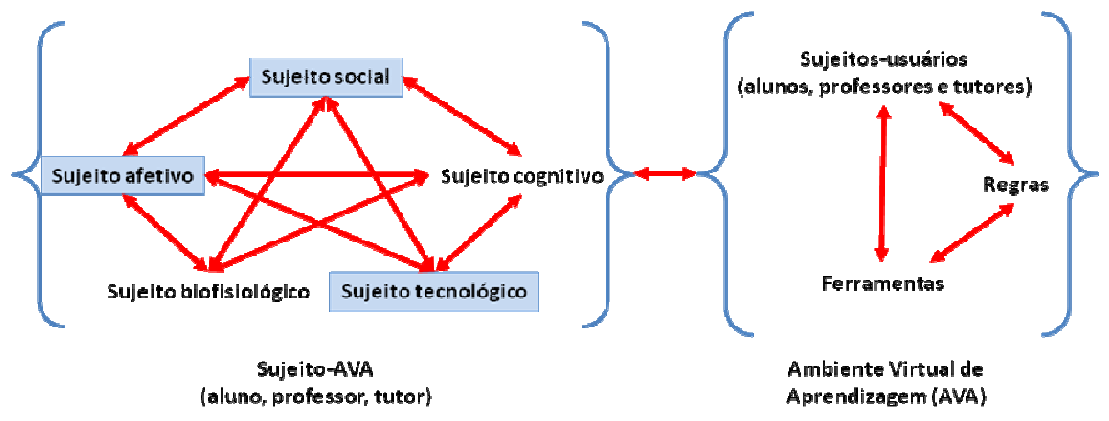

Figura 9. Representação da interação Sujeito-AVA e os sujeitos de estudo***

A dimensão biofisiológica do sujeito-AVA pode ser definida através de estudos sobre o comportamento observável do corpo, tais como gestos corporais, expressões facial, tensão muscular, condutividade da pele, respiração, ritmo cardíaco, temperatura e movimentos oculares, etc., por meio de sensores visuais (vídeo-câmeras), de áudio (microfones) e/ou fisiológicos (cadeiras sensíveis à pressão do corpo, luvas que captam a condutividade da pele, mouse sensível à "qualidade" de pressão, EEG, ECG, ERP, termógrafos, aparelhos para verificar pulsação, respiração e dilatação da pupila são exemplos para medir dados fisiológicos).

A dimensão tecnológica determina o quanto o sujeito-AVA está aberto às novas tecnologias. Faz referência ao conhecimento tecnológico que o sujeito-AVA deve suportar para comunicar-se e sentir-se participante do ambiente virtual. Mas, também, reconhece as limitações do sujeito-AVA com o ambiente. Neste trabalho, serão consideradas as dificuldades com a operacionalização do ambiente, os problemas técnicos e os conhecimentos de cunho tecnológico necessários para o uso do ambiente.

A dimensão social envolve a construção de uma comunidade virtual através das relações individuais ou interindividuais. É caracterizada pela interiorização das regras impostas pelo ambiente virtual, e pelas interações estabelecidas com outros sujeitos-usuários. A qualidade das interações pode ser analisada sob o ponto de vista de uma simetria entre a quantidade de acessos e a qualidade de relações formadas (intercâmbio social) (Bassani, 2006).

A dimensão cognitiva, por sua vez, faz referência aos processos de construção do conhecimento sobre o objeto de estudo (conteúdo, matéria, objeto de aprendizagem, etc.) e através dele.

A dimensão afetiva, enfatizada neste trabalho, caracteriza-se pela externalização ou não dos fenômenos afetivos acionados durante os processos que se seguem às outras dimensões. Assim, decidiu-se por tratar os estados de ânimo por serem dentre os fenômenos afetivos os mais representativos no âmbito da aprendizagem. Utilizam-se, para tanto, os indicadores estar animado, desanimado, satisfeito e insatisfeito (Longhi et alli, 2009).

A figura 10, através da rede semântica proposta por Bower (1981), ilustra parte dos estudos realizados pelas autoras para avaliar as conexões entre os diversos sujeitos constituintes do sujeito-AVA. 


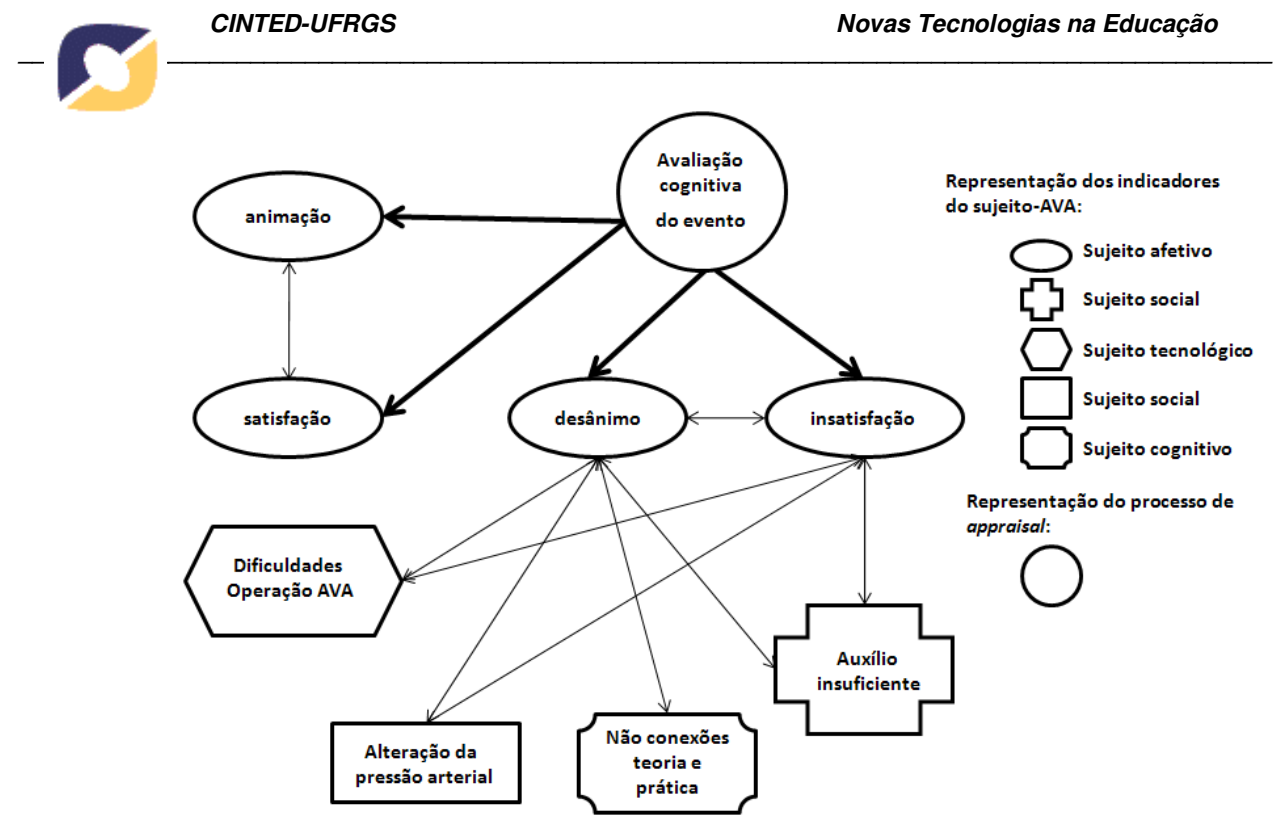

Figura 10. Indicadores do sujeito-AVA***

A dimensão biofisiológica e a cognitiva não serão tratadas na pesquisa ora em desenvolvimento, por serem objeto de estudo em projetos junto ao Programa de Pósgraduação em Informática na Educação da UFRGS. O primeiro encontra-se em estágio inicial, e o segundo encontra-se em constante discussão, cabendo destacar a contribuição de Bassani (2006).

\section{Considerações Finais}

Aprender é "uma função biológica desenvolvida nos seres vivos de certa complexidade, que implica produzir mudanças no organismo para responder às mudanças ambientais relevantes, conservando essas mudanças internas para futuras interações com o ambiente, o que exige dispor também de diferentes sistemas de memória ou representações de complexidade crescente" (Pozo, 2004 p. 36). Isso significa que, em face aos numerosos estudos sobre o papel da dimensão afetiva na aprendizagem humana, os fenômenos afetivos contribuem na representação interna do objeto de conhecimento, e afetam a maneira como o indivíduo aprende, toma decisões e se comporta nas interações sociais.

Com relação à aprendizagem, as dimensões afetivas influenciam tanto de modo favorável quanto desfavorável. No primeiro, o sentido de desafio, a persistência, o entusiasmo, a curiosidade, a satisfação da tarefa cumprida, favorecem o aluno na consolidação do conhecimento adquirido, motivando-o a seguir na obtenção de novos. No segundo, encontram-se o medo, a incerteza, a resignação, a ansiedade, a indiferença, a falta de autoconfiança, o aborrecimento, etc. podendo induzi-lo ao afastamento ou à desistência. $\mathrm{O}$ estado afetivo experimentado na realização de uma atividade é, em grande parte, determinado pelas características e conteúdo da tarefa, assim como da estratégia pedagógica aplicada.

Maehr (2001), ao referir que a motivação escolar relaciona-se aos aspectos afetivos do aluno, sugere que os estudos devem ser redirecionados: "se eles energizam [o aprendizado], de que forma o fazem? Se eles debilitam ou frustram, por que e quando o fazem? É preciso redescobrir o papel das emoções na motivação" (p. 184).

Percebe-se que as tecnologias digitais, principalmente em contexto virtual, promovem mudanças das relações entre os agentes de aprendizagem: professores, alunos e tutores. Por sua vez, as análises e estudos que se fazem necessários para acomodar estes novos paradigmas precisam de teorias que as validem. Com tal intuito, o presente trabalho enfatiza as contribuições de Scherer e de Piaget para efeito de análise e interpretação do sujeito afetivo em interação em AVA (Sujeito-AVA).

V. $7 \mathrm{~N}^{\circ}$ 3, dezembro, 2009 


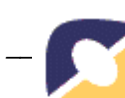

De fato, verifica-se que Piaget não concebe um processo de acomodação e assimilação sem ter como premissa a afetividade inerente, os valores do sujeito. Scherer, por sua vez, define estados de ânimo como processos e uma forma de analisar como se processam tais estados em um sujeito.

Assim, este estudo defende a importância da inferência dos estados de ânimo em ambientes virtuais de aprendizagem e, para tal, está em desenvolvimento, no âmbito do AVA ROODA, um instrumento apto a tal reconhecimento. Espera-se que esses espaços deixam de ser meros repositórios de conteúdos ou meios de comunicação, para, além disso, se re(pensar) possíveis modificações nas ações em EAD.

\section{Notas}

* Este trabalho vincula-se ao projeto de pesquisa "Mapeamento dos estados de ânimo do aluno no ambiente virtual de aprendizagem ROODA" em desenvolvimento no NUTED/UFRGS, com apoio do CNPq.

** A figura foi extraída de Bassani (2006).

**** A figura foi formulada pelas autoras.

1 Modelo pedagógico pode ser definido como um sistema de premissas teóricas que representa, explica e orienta a forma como se aborda o currículo, concretizando-se nas práticas pedagógicas, assim como nas interações professor-aluno-objeto de conhecimento (Behar, 2009).

${ }^{2}$ O ROODA (Rede cOOperativa de Aprendizagem), disponível em http://rooda.edu.ufrgs.br, é uma das plataformas disponibilizadas pela UFRGS para aulas presenciais e a distância.

${ }^{3}$ Dolle (1993) identifica os objetos naturais como aqueles relacionados à natureza (vegetais, minerais, animais, clima, etc.), e os artificiais, aqueles fabricados pelo homem.

${ }^{4}$ De um modo geral, estádio é um marco de uma evolução na direção do equilíbrio das ações e operações mentais. A duração do sujeito em cada estádio depende dos fatores individuais e do meio (Montangero \& Maurice-Naville, 1998).

${ }^{5}$ O conceito de appraisal foi introduzido por Magda B. Arnold em 1960. Inicialmente, o sujeito faz uma avaliação instantânea da situação. A emoção constitui o produto dessa avaliação. Quando a emoção é expressa, vem acompanhada do sentimento subjacente. Logo, ainda que o processo de avaliação seja inconsciente, seus efeitos são conscientes.

${ }^{6}$ Cluster, neste caso, pode ser definido como um grupo de posições de memória, agrupadas em um único local.

\section{Referências Bibliográficas}

ARANTES, V. A. Afetividade e Cognição: rompendo a dicotomia na educação. In: VIDETUR, n. 23. Porto/Portugal: Mandruvá, 2003.

BASSANI, P. B. S. Mapeamento das interações em ambiente virtual de aprendizagem: uma possibilidade para avaliação em educação a distância. Porto Alegre: PPGIE/UFRGS. Tese de Doutorado. 2006.

BECKER, F. O que é construtivismo? Revista de Educação - AEC, Brasília, DF, v. 21, n. 83, p. 7-15, 1992.

BEHAR, P. A. A lógica operatória e os ambientes computacionais. In: Anais do SBIE 1999 X Simpósio Brasileiro de Informática na Educação, Curitiba, PR. Novembro, 1999.

BERCHT, M.. Em direção a agentes pedagógicos com dimensões afetivas. Instituto de Informática. UFRGS. Tese de Doutorado. Porto Alegre. 2001.

BOWER, G.H. Mood and memory. American Psychologist, 36, 129-148. 1981.

V. $7 \mathrm{~N}^{\mathrm{o}}$ 3, dezembro, 2009 
DOLLE, J.M. Para além de Freud a Piaget: referenciais para novas perspectivas em psicologia. Petrópolis, RJ: Vozes. 1993.

DOLLE, J.M. De Freud a Piaget. Lisboa: Editores Moraes, 1979.

LONGHI, M. T.; BEHAR, P. A. e BERCHT, M. AnimA-K: recognizing student's mood during the learning process. In: WCCE 2009 - 9th IFIP World Conference on Computers in Education, Bento Gonçalves, RS, Brazil. July 27-31, 2009.

MAEHR, M.L. Goal theory is not dead-not yet, anyway: A reflection on the special issue. In: Educational Psychology Review 13 (2), pp. 177-185. 2001.

MAYER, J. D., \& HANSON, E. Mood-congruent judgment over time. Personality and Social Psychology Bulletin, 21, 237-244. 1995.

MONTANGERO, J. e MAURICE-NAVILLE, D. Piaget: ou a inteligência em evolução. (Trad.: Marques, T.B.I. \& Becker, F.). Porto Alegre: Artmed. 1998.

PERGHER, G. ; GRASSI, R. ; ÁVILA, L. M. ; STEIN, L. M.. Memória, humor e emoção. Revista de Psiquiatria do Rio Grande do Sul, v. 28, n. 1, p. 61-68, 2006.

PIAGET, J. Estudos sociológicos. Rio de Janeiro: Forense. 1973.

PIAGET, J. A epistemologia genética. (Trad. Caixeiro, N. C.) São Paulo: Abril Cultural. 1978.

PIAGET, J. Abstração reflexionante: relações lógico-aritméticas e ordem das relações espaciais. (Trad.: Becker, F. \& Silva, P.B.G.) Porto Alegre: Artes Médicas. 1995.

PIAGET, J. Inteligencia y afectividad. Buenos Aires: Aique, 2005.

SCHERER, K. R. Toward a dynamic theory of emotion: The component process model of affective states. Geneva Studies in Emotion and Communication, 1, 1-98. 1987.

SCHERER, K. R. Appraisal considered as a process of multilevel sequential checking. In Scherer, K.R., Schorr, A., \& Johnstone, T., (Eds) Appraisal Processes in Emotion: Theory Methods, Research. Oxford, New York: Oxford University Press, 92-129. 2001.

SCHERER, K. What are emotions? And how can they be measured? In: Social Science Information 44 (4), 695-729. 2005. 